\title{
Assessment of physical properties and sensory attributes of extruded corn snacks mixed with barley and supplemented with (guar and xanthan) gums.
}

\author{
F.A. Ismail, N.H. El-Gazar and D.M. Ali
}

Department of Food Technology, Faculty of Agriculture, Cairo University, Egypt.

\section{ABSTRACT}

Corn snacks mixed with barley flour in addition to guar and xanthan gumswere evaluated for their physical and sensory properties. Snacks samples were processed using corn grits mixed with $5 \%$ barley flour and (0.5-1\%) guar gum or xanthan gum using traditional extrusion system conditions. The extruded samples were tested instrumentally direct after processing and at 3, 6, 9 and 12 months' storage (at room temperature) for bulk density, expansion ratio, shear force (hardness) and color. Sensory evaluation was made for snacks color, chewiness, surface characteristics and general appearance. Samples fortified with guar gum recorded the highest value of expansion ratio and shear force $2.82 \mathrm{~cm}$ and $16.1 \mathrm{~kg} / \mathrm{cm}^{2}$ respectively. Xanthan gum had the lowest texture shear force values $14.7 \mathrm{~kg} / \mathrm{cm}^{2}$ comparing control $15.3 \mathrm{~kg} / \mathrm{cm}^{2}$ and recorded $2.61 \mathrm{~cm}$ expansion comparing $2.25 \mathrm{~cm}$ for control. Adding gum increased bulk density values from $0.52 \mathrm{~g} / \mathrm{cm}^{3}$ up to $0.69 \mathrm{~g} / \mathrm{cm}^{3}$. Sample mixed with guar and xanthan gums recorded the higher acceptability scores by panelists than other tested samples.

Key words: snacks, extrusion, barley flour, guar gum, xanthan gum, physical properties. 


\section{INTRODUCTION}

Snacks became an important part of the eating habits of the majority of the world's population. Basically, they were prepared from natural ingredients or different components according to predesigned perfect plans in order to yield products with specified functional properties in addition to health benefit for consumers (Thakur and Saxena, 2000).

Faraj et al, (2004) reported that, extrusion technology, in recent times, has become one of the major processes for producing varieties of food, cereals are common ingredients in extruded products and barley flour has been incorporated into some extruded human food. Some of the advantages that had been attributed to this technique include low cost, high productivity, versatility and unique product shapes. Extrusion-cooked products such as snacks or breakfast cereals contain significant calories amounts. One of the strategy ideas followed by the food industry companies was to reduce caloric energy of foods and increase their content of dietary fiber (Anderson et al., 2009). Eating between meals (snacking) was commonly seen in various countries around the world. Some studies found that this eating behavior linked with overweight and obesity, whereas others have shown that snacking could be helpful for energy regulation (Green et al., 2017).

Dietary fibers are carbohydrates that are resistant to digestion and absorption in the human small intestine and undergo complete or partial fermentation in large intestine. Diets moderate to high in fiber help reduce the risk of cardiovascular disease, diabetes and cancer as reported by WHO (2003). In producing such foods of acceptable quality, it is always a challenge to optimize the potential health benefit while 
retaining the consumer acceptability. Gums, agar, alginate, galactomannan and pectin were soluble dietary fibers, in comparing with the insoluble types like cellulose and lignin (Brennan et al., 2002). Guar gum was a water-soluble, non-starch polysaccharide galactomannan found in the endosperm of the seed from the Indian cluster bean Cyamopsis tetra-gonoloba. Galactomannan consisted of a $\beta$-(1-4)-linked Dmannopyranosyl backbone, partially substituted with $\alpha-(1-$ 6)-linked D-galactopyranosyl side chains (Meir and Reid, 1982).

In contrast, xanthan gum is an anionic extracellular polysaccharide produced by fermentation of the bacterium Xanthomonas campestris. Xanthan has a $(1 \rightarrow 4)$-linked $\beta$ D-glucan (cellulose) backbone solubilized by attachment of charged trisaccharide side chains $[\beta-D \quad$-mannopyranosyl- $(1 \rightarrow 4)$ $\beta$-D-glucur-onopyranosyl$(1 \rightarrow 2)-6-O$-acetyl- $\beta$-D-manno- pyranosyl] at O-3 of alternate glucose residues (BeMiller, 2011). It is well known that hydrocolloids (gums) can alter the gelatinization and rheological characteristics of starches and improve texture and appearance of final baked products (Mariottiet al., 2009). Traditionally, gums like guar, xanthan and carboxymethyl cellulose (CMC) were widely used in starch-containing foods to control rheological and textural properties of foods, as well as to improve moisture retention and stability (PérezCarrilloa et al., 2017). Different types of gums were frequently used for improving the texture and structure of food in general, and bakery products in particular. So, most gums were qualified for "natural" labeling in most snacks products in the commercial markets. These features, along with the fatreplacement properties of gums, lead to a healthy imagination of snacks that contain specific gums (Pszczola, 1999). In 
addition, regulations approved a health claim that consuming a diet low in saturated fat and cholesterol may reduce the risk of heart diseases. The effect of $1 \%$ addition of xanthan gum on the structural and the mechanical properties of corn flour pellets expanded by microwave heating was studied by Gimeno et al. (2004) they found that the addition of gum significantly improved the shape, structure, and texture. Also, the inclusion of non-starch polysaccharides in the formulation of extruded products has resulted in changes in physical characteristics (such as texture) as well as starch digestibility.

Moreover, Parade et al. (2011) observed the effect of guar gum (0-10\%) added to flour (maize, potato, rice and wheat) prior to extrusion on the microstructure, physical properties (texture, expansion, density, and pasting) and nutritional properties. They reported that the inclusion of guar gum did not decrease starch digestibility, but at $10 \%$ guar gum adding; rapidly digestible starch increased by $24 \%, 15 \%$, $25 \%$ and $43 \%$ in maize, potato, rice and wheat flour- based products, respectively. Also, Torres et al. (2013) observed that industrial processes involving operations such as baking and extrusion of flour based products, thickening and gelling agents depended on starch gelatinization. The use of additives like hydrocolloids modifies the starch gelatinization behavior. Each hydrocolloid affects in a different way the thermal properties of starch. This fact could be attributed to several factors such as the molecular structure of hydrocolloids and ionic charges of both starches and hydrocolloids.

Moreover, color is an important characteristic of extruded foods. Color changes can give information about the extent of browning reactions such as caramelization, Maillard reaction, degree of cooking and

Bulletin of the National Nutrition Institute of the Arab Republic of Egypt. December 2017(50) 4 
pigment degradation that take place during the extrusion process (Altan et al., 2008).

During the production of snacks, gums were used as fatsubstitution. Fat in flour-dough improved mouth feel, tenderness, shininess and the related color features in bakery products. But, fat because of its high-caloric source had replaced by a mixture of gums in many baking products (Jia et al., 2008). Also, Aravind et al. (2012) studied the adding of Guar gum in the mixture of durum wheat spaghetti and its sensory properties especially pasta color, they found that the color affected by guar gum with increase in redness at $10 \%$ guar and above, while decreases in brightness and yellowness occurred

above 10\%guar.The $20 \%$ guar samples had the lowest $\mathrm{L}$ and $\mathrm{b}$ and the highest a. In addition, there were relatively minor impacts of guar gum with $2.5 \%$ and $5 \%$ substitution on technological properties, however at $10 \%$ guar and especially above $20 \%$, pasta became softer, stickier, had higher cooking loss, absorbed more water and was duller and less yellow. Moreover, Jia et al. (2008) studied the effect of Xanthan and Arabic gums on sensory attributes especially, the color ( $\mathrm{L}, \mathrm{a}$ and $\mathrm{b}$ parameters) of Chinese moon cake processed from almond flour and maltitol syrup. They reported that reduction of oil or addition of gums had no significant effects on the color parameters. In contrast, the sensory panel's decisions were in agreement with the highest values of cohesiveness, chewiness, a value of color, in addition to less hardness and $\mathrm{L}$ values.

The objective of the study was to evaluate the physical and sensory properties of extruded corn snacks blended with barley flour and gums. 


\section{MATERIALS \& METHODS}

\section{Materials}

Yellow corn grits (Zea maize L.), barley flour (Hordeum vulgare L.) iodized edible fine salt, white sucrose sugar and Anato powder (E106b) were obtained from Mass Food Co. 6 October city, Egypt. Guar and xanthan gums were bought from Oxford lab. in Cairo.

\section{Preparation different corn blends}

Essential corn grits and raw ingredients (salt, sugar and Anato powder with equal percentages) were used; also (0.5-1\%) gums and barley flour at $5 \%$ were added as follow:

Control: corn grits

Sample 1: replacement of corn grits by $1 \%$ xanthan gum and $5 \%$ barley flour.

Sample 2: replacement of corn grits by $1 \%$ guar gum and $5 \%$ barley flour.

Sample 3: replacement of corn grits by $(0.5 \%$ xanthan and
$0.5 \%$ guar) gums and $5 \%$ barley flour.

\section{Extrusion process}

Co-rotating twin screw (BC-82) extrusion system was used as reported by Gimeno et al. (2004) to prepare the three puffed snacks samples from different blends. The extrusion conditions were: Feed rate as $50 \mathrm{gm} / \mathrm{min}$, screw speed as308rpm, cutter speed as 70 rpm and moisture content were $15 \%$. Die diameter was $0.4 \mathrm{~mm}$.Temperature profiles were: $75^{\circ} \mathrm{C}$ to maximum $80^{\circ} \mathrm{C}$ and $60^{\circ} \mathrm{C}$ at final under pressure of $1.0 \mathrm{~Pa}$. After extrusion, corn snacks pops samples were dried in oven at $180^{\circ} \mathrm{C}$ for seconds. Then cooled to $30^{\circ} \mathrm{C}$. Samples were packaged in high density poly ethylene packages and storage at room temperature for lab.and tested at time intervals of $0,3,6,9$, and 12 months.

\section{Bulk density (BD)}

The method of Park $\boldsymbol{e t}$ al (1993) was used for calculating the bulk density of extrudates, 
whereas, a $250 \mathrm{ml}$ graduated cylinder was tired and filled with puffed extrudates. BD was calculated as weight of sample/unit of volume $\left(\mathrm{g} / \mathrm{cm}^{3}\right)$.

\section{Expansion ratio(ER)}

Expansion ratios of extrudates were determined as described by Gujska and Khan (1990) ER was calculated as follows:

\section{ER = Diameter of extruded} product / die of extruder

\section{Texture (Shear force (SF))}

The Warner-Bratzler shear force apparatus was used as reported by Herring (1976) to measure the crispiness of extrudates. The shear force values $\left(\mathrm{kg} / \mathrm{cm}^{2}\right)$ were reported for each sample. Low shear force values indicated high weakness of extrudates (high crispiness) and vice versa the high shear force related to hardness of extrudates (low crispiness).

\section{Color measurement}

The color of snacks extrudates after different storage time intervals was measured using Hunter lab Color, CHROMA-meter model CR400, China. Hunter color values were defined as described by Park et al, (1993). Hunter L values (0 = black, $100=$ white) were indication of lightness, Hunter a values measure chromaticity with positive values indicating redness and negative values greenness, and Hunter $b$ values with positive values indicating yellowness and negative values for blueness.

\section{Sensory evaluation of processed} snacks:

Sensory evaluations were carried out after snacks processing and after different time intervals. Ten panelists helped in obtaining the acceptable values of texture and color with 0 to 10 scores where $0=$ no $\quad$ response, $\quad 10=$ strong response and asstated by Abu- 
Foul (1990) for the following characteristics:

Color: Yellow, yellowish and brown Chewiness: Tender, nearly tender, slightly hard and hard.

Surface characteristics: Smooth, semi rough and rough.General appearance: Excellent, good, satisfactory and unsatisfactory.

\section{Data analysis}

Statistical analysis was done for all parameters by using analysis of variance (ANOVA).

\section{RESULTS \& DISCUSION}

Physical characteristics of corn- snacks mixed with gums

Bulk Density (BD)

Bulk density is an important property of the extrudate products. The size, volume, and pore shape irregularities inside the extrudates were generated because of the water evaporation and the effect of ingredient inside snacks structure (Chevanan et al., 2007).Results given in Table (1) showed that addition of $1 \%$ guar gum had increased the density of snacks from $0.52 \mathrm{~g} / \mathrm{cm}^{3}$ in control sample to $0.66 \mathrm{~g} / \mathrm{cm}^{3}$ comparing, where percentage of change was $26.92 \%$. Also, samples with $1 \%$ xanthan had increased density to $\left(0.69 \mathrm{~g} / \mathrm{cm}^{3}\right)$ and percentage of change was $32.69 \%$.These results in agreement with Maga and Fapojuwo (1988) who reported that addition of cellulose gums and $\mathrm{XG}$ to corn grits before extrusion resulted in increased density for all extrudates. Figure (1) observed that values of bulk density were increased over time in all tested samples. Wang et al. (2007) described that guar gum might interact with amylose and amylopectin upon heating, leading to increase in the system paste viscosity duringextrusionwhich can be related to bubble formation. Moreover, values of our results, showed that the inclusion of guar gum increased the density of extruded products and that in 
agreement with Brennan et al. (2008) reported that inclusion of guar gum increased the density of extruded products, possibly because it did not dilute starch and Guy. (2001) who found the extrudates with higher BD requires less space and packing.

\section{Expansion ratio(ER)}

Results in Table showed that the ER of final products varied from 2.25 to $2.82 \mathrm{~cm}$ depending on type and level of added gums. Sample2 which fortified with $1 \%$ guar gum showed the highest value $(2.82 \mathrm{~cm})$ and significantly different compared with control and other samples. Garber et al. (1997) showed that the larger particle size caused the lower in the degree of expansion of corn extrudates. Also, Figure (2) showed that expansion values were slightly decreased in all samples during storage period. Gimeno et al. (2004) observed that the effect of $\mathrm{XG}$ addition $(1 \%)$ to corn flour resulted in more uniform shaped samples than the corn flour only. Moreover, Parade et al. (2011) reported that, the effect of soluble fiber on the expansion of extruded products also appears to depend on the type of cereal to which the fiber is added.

\section{Shear force (SF)}

The effects of adding gums on the texture properties of snacks samples were shown in Table (1). The results observed that adding $1 \%$ guar gum increased the shear force to 16.1 $\mathrm{kg} / \mathrm{cm}^{2}$ compared with control-sample $\left(15.3 \mathrm{~kg} / \mathrm{cm}^{2}\right)$, where percentage of change was $5.2 \%$. However, the most crispness of samples reported $\left(14.5 \mathrm{~kg} / \mathrm{cm}^{2}\right)$ was for sample fortified with guar and xanthan together, where percentage of change was ($5.4 \%$ ). Wang et al. (2007) reported that changes of texture appeared to be related to the capacity of guar gum that enhanced or modified gelatinization and retrogradation behavior of starch. 
Moreover, Robin et al. (2012) reported that fiber type and quantity effect the texture of extruded products. Insoluble fiber significantly reduced expansion volumes and increased density of extruded products, leading to harder textures. Also, the results in figure (3) showed increasing trend in shear force values especially with $1 \%$ GG. But, shear force values for samples that containing $\mathrm{XG}$ had approximately the same value and trendas control sample.

Gimeno et al. (2004) found significant effect of xanthan gum addition on the texture of the microwave-expanded samples and it was a reason for significantly lower variability in the mechanical properties as compared with the samples without gums. This also was in agreement with the opinion of Jia et al. (2008) who reported that gums could absorb water and made the molecules tightly or the reverse happened, so the addition of gums decreased the hardness of products from 18.0 to $16.7 \mathrm{~kg} / \mathrm{cm}^{2}$ in Chines moon cake.

\section{Color evaluation}

Data in Table (1) and Figure (4) showed the color properties of different blends after extrusion and during storage period intervals. There was not obvious effect in lightness. But, some reduction in Hunter "L" values were noted for samples which fortified with guar gum and also with both of gums together comparing samples that containing $1 \% \mathrm{XG}$. However, control sample recorded the highest yellow nessvalue (b). The same trend was observed by Jin et al.(1994) who reported that the reduction in redness and yellowness with increasing fiber contents might be explained as the possibility that fibrous gumswere lighter in color and had much less pigments than that of the corn meal itself. Also, Jia et al. (2008) observed a decrease in "L" value with increased the 
adding of xanthan gum to Chinese mooncake by $0.1 \%$ to $0.3 \%$. But, "b" and "a" value recorded an increase in the same products with increasing the gum ratio. Delgado-Nieblas et al. (2015) reported that the lowest values of $\mathrm{L}$ at low moisture content levels could be due to a greater friction of the material within the extruder, causing polymerization of the gum and starch molecules and formation of sugars which could have suffered caramelization and/or Maillard reactions and thus darkening the product. Moreover, and according to figure (4), color parameter (b) values were decreased gradually with storage time. This decrease

Sensory evaluations of corn snacks mixed with gums

The scores of panelists for snacks sample characteristics were showed in Table (2), where samples fortified with both of gums recorded higher scores in most characteristics with storage time. Yang, et al. (2002) and was the same with all samples containing gums, but GG samples had the medium values. Aravind et al. (2012) explained that when added 5\%guar gum during extrusion process for durum wheat spaghetti there were decreased in $b$ values from 47.47 to 47.05 . The results in table (1) observed that adding amount of guar gum caused higher in snacks yellowness than xanthan gum and snacks with guar only was more gold yellow than Xanthan gum plus guar gum. However, during storage bvalue (yellow color) showed down ward trends it decreased in all tested snacks samples and control as well.

Perry et al. (2003) reported that gums as a carbohydrate had stronger adhesion and improved the structure of moon cake by the property of absorbing water, which made a food system smoother and become similar to function of fat. In our study and for snacks surface smoothness, the highest 
values recorded for snacks mixed with xanthan gum plus guar gum, but, it decreased at 12 months' storage. Also, smoothness tended to increase with xanthan gum alone than with guar gum. Gimeno et al. (2004) studied the effect of addition xanthan gum on the structural and the mechanical properties of corn flour pellets. They found that pellets expanded by micro-wave heating significantly and the shape improved. Also, Souther (2005) reported that guar gum did exhibit interactions with starches and other gums such as xanthan. The interaction resulted in a synergistic increase in viscosity. The prime functions of guar gum in foods are to bind water,

to, improve mouthfeel, reduce chewiness, improves mixing tolerances, and to improve shelf life through moisture retention. In addition, Jia et al. (2008) reported that increasing the amount of XG and Arabic gum resulted in an increase in chewiness values from 13.7 to 15.0 for moon cake. Chewiness values of corn grits fortified with gums extrudates were higher than corn grits extruded samples and that was in agreement with Shao et al. (2015) who reported that addition of guar and xanthan gums together improved hardness but increased chewiness values. Chewiness was also increased by the addition of xanthan gum in eggless cakes. Also, table (2) observed that sensory evaluation scores of all snacks decreased gradually, which could be due to the chemical reaction or the absorption of some moisture on prolonged storage time. The panelists recorded excellent scores for all xanthan gum snacks samples; whether added alone or mixed with guar gum.

On the other hand, the relationship between instrumental parameters and sensory properties of snacks samples were shownin figures (5), (6) and (7).In figure (5), instrumental yellow color values 
(b-values) was strongly correlated with panelist color scores $\left(\mathrm{R}^{2}=0.7702\right)$. Also, in figure (6), there were increasing trend towards instrumental shear-force values and panelists scores for chewiness with strong correlation value $\left(\mathrm{R}^{2}=-13.35\right)$. However, in figure (7) week relationship between overall

\section{REFERANCES}

\section{Abu-Foul NSI. (1990):}

Physico-chemical, nutritional and technological studies on food uses of glanded and glandless cottonseed protein. Ph.D. Thesis, Fac. Of Agric., Alex. Univ., Egypt.

\section{Altan A; Mccarthy KL andMaskan M (2008): \\ Evaluation of snack foods from barley-tomato pomace blends by extrusion processing. Journal of Food Engineering, 84: 231-242.}

snacks were appearance scores and the related property (expansion ratio values). From the previous demonstrated correlation, instrumental measurement for color and shear force can be used and directly reflect the sensory attribute for color and chewiness.

Anderson JW; Baird P; Davis JrRH; Ferreri $S$ and Knudtson M (2009):

Physiochemical and sensory evaluation of extruded high fiber barley cereals. Cereal Chem., 71:91-95.

Aravind N; Sissons $M$ and Fellows M (2012):

Effect of soluble fibre (guar gum and carboxymethylcellulose) addition on technological, sensory and structural properties of durum wheat spaghetti. Food Chem., 131:893-900. 
BeMiller JN (2011):

Pasting, paste, and gel properties of starchhydrocolloid combinations.

Carbohydrate Polymers, 86(2):386-423.

\section{Brennan CS; Tudorrica CM} and Kuri V (2002):

Soluble and insoluble fibers (non-starch polysaccharides) and their effects on food structure and nutrition. Food Industry Journal, 5:261272.

Brennan M; Monro JA and Brennan CS (2008):

Effect of inclusion of soluble and insoluble fibers into extruded breakfast cereal products made with reverse screw configuration.

International Journal of Food Science and Technology, 43: 22782288.
Chevanan N; Rosentrater K A and Muthukumarappan K (2007):

TwinScrew Extrusion Processing of Feed Blends Containing Distillers Dried Grains with Solubles (DDGS). Cereal Chemistry, 84: 428-436.

Delgado-Nieblasa CI; ZazuetaMoralesa JJ; GallegosInfanteb JA and Carrillo-Lópeza A(2015): Elaboration of functional snack foods using raw materials rich in carotenoids and dietary fiber: effects of extrusion processing. CyTA Journal of Food, Vol. 13, No. 1, 69-79.

Faraj A; Vasanthan $T$ and Hoover R (2004):

The effect of extrusion cooking on resistant starch formulation in waxy and regular barley flour. Food Research International. 37:517-525. 
F.A. Ismail, N.H. El-Gazar and D.M. Ali

Garber BW; Hsieh F and Huff

HE (1997):

Influence of particle size

on the twin-screw

extrusion of corn meal.

Cereal Chemistry, 74 (5), 656-661.

\section{Gimeno E; Moraru CI and} Kokini JL (2004):

Effect of Xanthan Gum and $\mathrm{CMC}$ on the structure and texture of corn flour pellets expanded by microwave heating. Cereal Chemistry, 81:100-107.

\section{Green H; Siwajek P and}

Roulin A (2017):

Use of nutrient profiling to identify healthy versus unhealthy snack foods and whether they can be part of a healthy menu plan. Journal of Nutrition\&Intermediary Metabolism, 9:1-15.

Gujska E and Khan K (1990): Effect of temperature on properties of extrudates from high starch fraction of navy, pinto and garbanzo bean. Journal of Food Science, 55 (2): 466469.

\section{Guy R (2001):}

Snack foods. In Extrusion Cooking. Technologies and Appli-cations, 1st ed.; Guy, R., Ed.;CRC: Boca Raton, FL, USA, pp. 161181.

Herring HK (1976):

Evaluation of Beef

Texture In:" Objective

Methods for Food Evaluation", A symposium

7 National Academy of Sci., Washington D.C. U.S.A.

Jia C; Kim Y; Huang W and Huang G (2008):

Sensory and instrumentalassessment of Chinese moon cake: Influences of almond flour, maltitol syrup, fat and gums. Food Research International, 41: 930936. 
Jin Z; Hsieh F and Huff HE (1994):

Extrusion cooking of corn meal with soy, fiber, salt and sugar. Cereal Chem., 71(3): 227-234.

\section{Maga JA, and Fapojuwo OO} (1988):

The effect of various hydrocolloids on some physical properties of extruded corn grits. International Journal of Food Science and Technology, 23: 49-56.

\section{Mariotti M; Lucisano M;} Pagani MA and Ng PK (2009):

The role of corn starch, amaranth flour, pea isolate, and Psyllium flour on the rheological properties and the ultrastructure of gluten-free doughs. Food Research International, 42(8): 963-975.

\section{Meir H, and Reid JSG (1982):}

Reserve polysaccharides other than starch in higher plants. In F. A. Loewus\&
W. Tanner (Eds.), Enccyclopaedia of plant physiology (pp, 418-471). New York: SpringerVerilog.

Park J; Kim BK and Rhee KC (1993):

Single-screw extrusion of defatted soy flour, corn starch and raw beef blends. Journal of Food Science, 58(1): 9-20.

Pérez-Carrilloa E; GonzálezFernándezb AG; Morales-Garzab MA and Treviño-Garzab E (2017):

Effect of sodium stearoyl2-lactylate, carboxymethyl cellulose and guarxanthan gums on muffins enriched with soybean milk powder and amaranth flour. CyTA-Journal of food, 15(4): 538-543.

Perry JM; Swanson RB; Lyon BG and Savage EM (2003):

Instrumental and sensory assessment of oatmeal and 
chocolate chips cookies modified with sugar and fat replacers. Cereal Chemistry, 80:45-51.

Prada J; Aguilera JM and Brennan C (2011):

Effect of guar content on some physical and nutritional properties of extruded products. Food Technol., 103: 324-332

Pszczola DE (1999):

Starches and gums move beyond fat replacement. Food Technol., 53: 74-80.

\section{Pobin F; Dattinger S; Boire A;} Horvat M; Schuchmann HP and Palzer S (2012):

Elastic properties of extruded starchy melts containing wheat bran using on-line rheology and Dynamic Mechanical Thermal Analysis. Journal of Food Engineering, 109(3): 414-423.

\section{Shao YY; Lin KH and Chen YH (2015):}

Batter and product quality of eggless cakes made of different types of flours and gums. Journal of Food Processing and Preservation, 39(6): 29592968.

\section{Souther BJ (2005):}

The Effect of Xanthan Gum and Guar Gum on Enhancing the Quality and Preventing Lipid Rancidity in Yeast Bread Supplemented with Flaxseed. M.Sc. Thesis, Faculty of Virginia Polytechnic Institute and StateUniversity, Blacksburg, Virginia. 80pp.

Thakur S and Saxena DC (2000):

Formulation of extruded snack food (Gum based cereal-Pulseblend):

Optimization of ingredient levels using response surface methodology, Lebensm. Wiss. Technol., 33: 354-361., 
Torres MD; Moreira R; Chenlo F and Morel MH (2013):

Effect of water and guar gum content on thermal properties of chestnut flour and its starch.33:192-198.

\section{Wang J; Jin $Z$ and Yuan $X$} (2007):

Preparation of resistant starch from starch-guar gum extrudates and theirproperties. Food Chemistry, 101:20-25.
WHO (2003):

Diet, nutrition and the prevention of chronic diseases. Report of a joint FAO/WHO expert consultation. World Health Organization.

\section{Yang M D; Yu YL and Geo F} (2002):

The advance of studies of fat replacement in food production. Food Science,23:310-314 
Table.1. Physical properties of corn snacks mixed with barley and gums after extrusion process (mean value*)

\begin{tabular}{|c|c|c|c|c|c|c|}
\hline \multirow[t]{2}{*}{ Snacks mixtures** } & \multirow{2}{*}{$\begin{array}{c}\text { BD } \\
\left(\mathrm{g} / \mathrm{cm}^{3}\right)\end{array}$} & \multirow{2}{*}{$\begin{array}{l}\text { ER } \\
(\mathbf{c m})\end{array}$} & \multirow{2}{*}{$\begin{array}{c}\mathrm{SF} \\
\left(\mathrm{Kg} / \mathrm{cm}^{2}\right)\end{array}$} & \multicolumn{3}{|c|}{ Hunter color values**** } \\
\hline & & & & $\mathbf{L}$ & $\mathbf{a}$ & $\mathbf{b}$ \\
\hline $\begin{array}{l}\text { Control; corn grits } \\
\text { only }\end{array}$ & $0.52^{\mathrm{c}}$ & $2.25^{\mathrm{d}}$ & $15.3^{\mathrm{b}}$ & $72.16^{c}$ & $3.37^{\mathrm{a}}$ & $28.99^{a}$ \\
\hline $\begin{array}{l}\text { corn } \\
\text { grits }+5 \% \mathrm{BF}+1 \% \mathrm{XG}\end{array}$ & $0.69^{\mathrm{a}}$ & $2.61^{b}$ & $14.7^{\mathrm{c}}$ & $73.21^{\mathrm{a}}$ & $2.56^{\mathrm{c}}$ & $23.95^{\mathrm{d}}$ \\
\hline $\begin{array}{l}\text { corn } \\
\text { grits+5\% BF+1\% GG }\end{array}$ & $0.66^{\mathrm{ab}}$ & $2.82^{\mathrm{a}}$ & $16.1^{\mathrm{a}}$ & $72.41^{b}$ & $2.75^{\mathrm{b}}$ & $25.39^{c}$ \\
\hline $\begin{array}{l}\text { corn } \\
\text { grits+5\% } \mathrm{BF}+0.5 \% \\
\text { GG+0.5\% XG } \\
\end{array}$ & $0.62^{\mathrm{b}}$ & $2.33^{\mathrm{c}}$ & $14.5^{\mathrm{c}}$ & $72.33^{b}$ & $2.69^{b}$ & $24.99^{b}$ \\
\hline
\end{tabular}

*Mean within each column with different letters are significantly different $(p<0.01)$

** BF: Barley Flour, GG: Guar Gum,XG: Xanthan Gum, BD: bulk density, ER:

expansion ratio and $S F$ : shear force.

***L: lightness, $a$ : Redness and $b$ : yellowness. 
Fig.1. Changes in Bulk density $\left(\mathrm{g} / \mathrm{cm}^{3}\right)$ values of snacks samples during storage at room temperature.

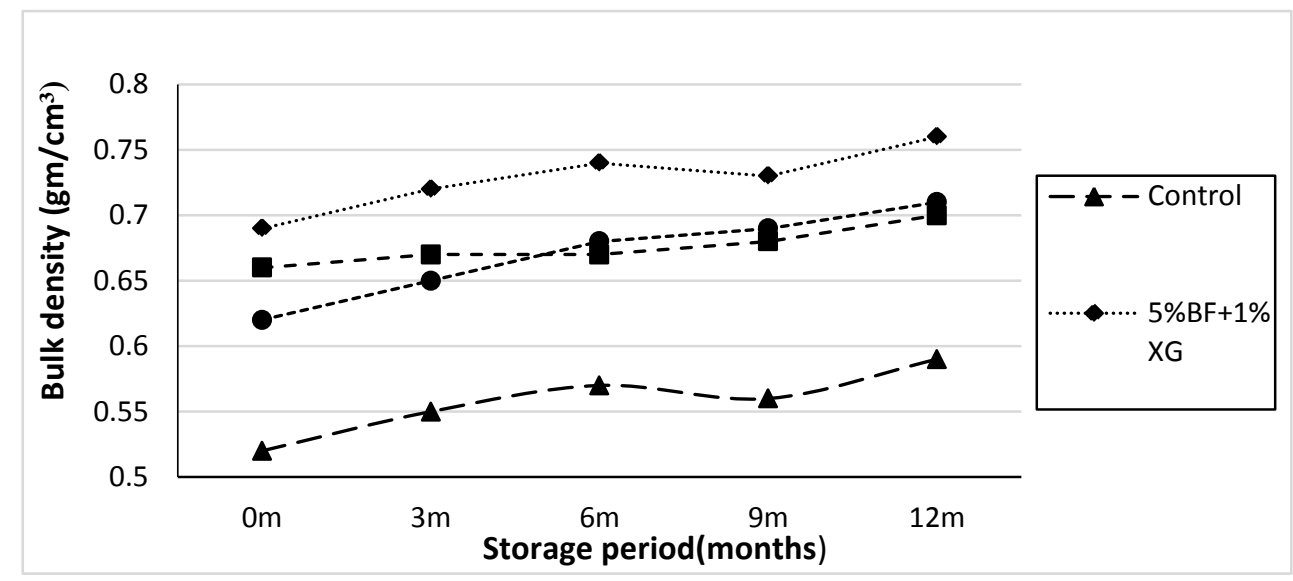

Fig.2. Changes in Expansion ratio (cm) values of snacks samples during storage at room temperature.

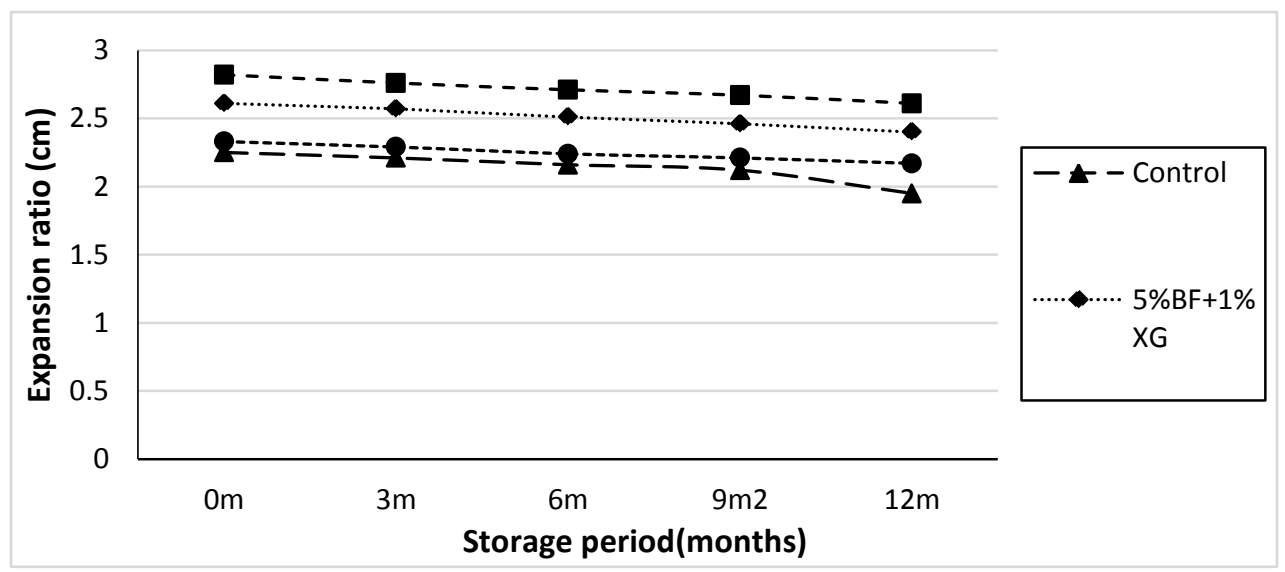

Bulletin of the National Nutrition Institute of the Arab Republic of Egypt. December 2017(50) 20 
Fig.3. Changes in Shear force $\left(\mathrm{kg} / \mathrm{cm}^{2}\right)$ values of snacks samples during storage at room temperature

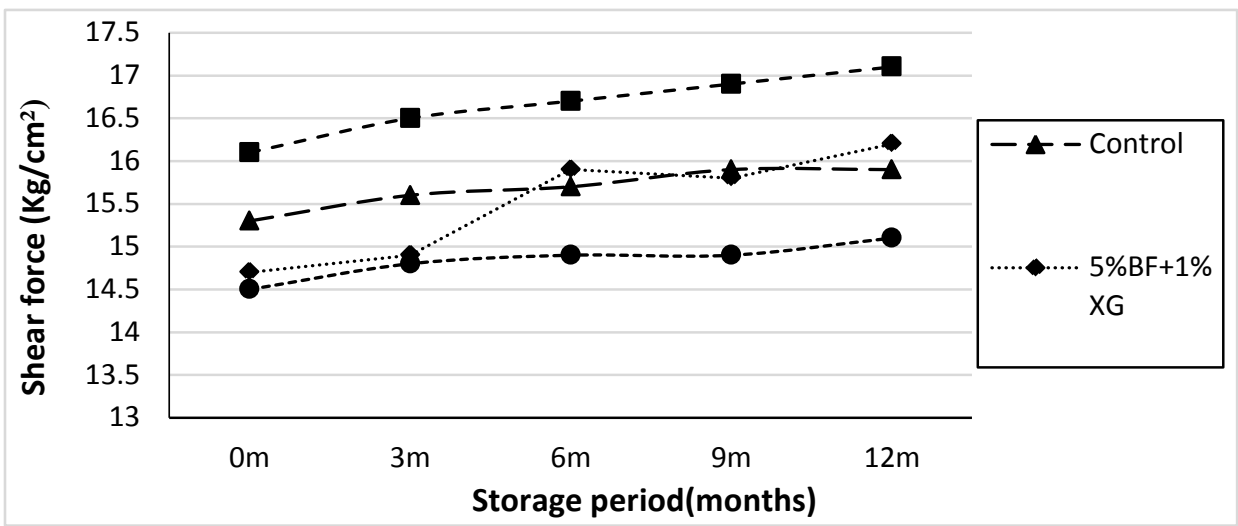

Fig.4.Changes in b- values of snacks samples during storage at room temperature.

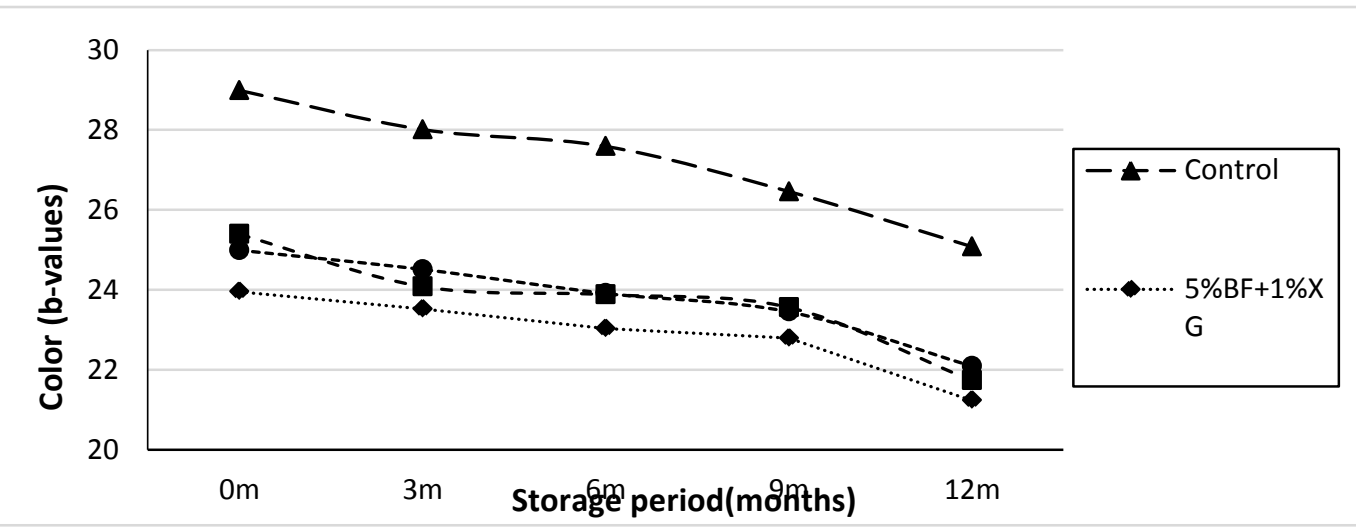

Bulletin of the National Nutrition Institute of the Arab Republic of Egypt. December 2017(50) 21 
Table.2. Sensory evaluation scores of corn snacks mixed with barley and gums during storage at room temperature (mean value*

\begin{tabular}{|c|c|c|c|c|c|}
\hline \multirow[t]{2}{*}{ Characteristics } & \multirow{2}{*}{$\begin{array}{l}\text { Storage } \\
\text { period } \\
\text { (month) }\end{array}$} & \multicolumn{4}{|c|}{ Snacks samples** } \\
\hline & & $\begin{array}{l}\text { Control; } \\
\text { Corn } \\
\text { grits only }\end{array}$ & $\begin{array}{l}\text { Corn } \\
\text { grits }+5 \% \\
\text { BF+1\% } \% \text { G }\end{array}$ & $\begin{array}{l}\text { Corn } \\
\text { grits }+5 \% \\
\mathrm{BF}+\mathbf{1 \%} \% \\
\mathrm{G}\end{array}$ & $\begin{array}{l}\text { Corn } \\
\text { grits+5\% } \\
+\mathbf{B F}+\mathbf{0 . 5 \%} \\
\mathbf{G G + 0 . 5 \%} \\
\text { XG }\end{array}$ \\
\hline \multirow[t]{5}{*}{ Color } & Zero & $9.00^{\mathrm{a}}$ & $7.00^{b}$ & $7.75^{b}$ & $7.75^{b}$ \\
\hline & Three & $8.75^{\mathrm{a}}$ & $7.00^{c}$ & $7.50^{\mathrm{bc}}$ & $7.75^{b}$ \\
\hline & Six & $8.00^{\mathrm{a}}$ & $6.75^{\mathrm{c}}$ & $7.25^{\mathrm{bc}}$ & $7.50^{\mathrm{ab}}$ \\
\hline & Nine & $7.50^{\mathrm{a}}$ & $6.50^{b}$ & $7.00^{\mathrm{ab}}$ & $7.25^{\mathrm{a}}$ \\
\hline & Twelve & $7.25^{\mathrm{a}}$ & $6.25^{b}$ & $6.75^{\mathrm{ab}}$ & $7.00^{\mathrm{a}}$ \\
\hline \multirow[t]{5}{*}{ Chewiness } & Zero & $6.00^{c}$ & $8.25^{\mathrm{a}}$ & $7.50^{b}$ & $8.00^{\mathrm{ab}}$ \\
\hline & Three & $6.00^{c}$ & $8.00^{\mathrm{a}}$ & $7.25^{b}$ & $8.00^{\mathrm{a}}$ \\
\hline & Six & $5.50^{b}$ & $7.50^{\mathrm{a}}$ & $6.00^{b}$ & $7.25^{\mathrm{a}}$ \\
\hline & Nine & $5.50^{b}$ & $6.75^{\mathrm{a}}$ & $5.50^{\mathrm{b}}$ & $7.00^{\mathrm{a}}$ \\
\hline & Twelve & $5.00^{c}$ & $6.25^{b}$ & $5.50^{c}$ & $7.00^{\mathrm{a}}$ \\
\hline \multirow{5}{*}{$\begin{array}{l}\text { Surface } \\
\text { characteristics }\end{array}$} & Zero & $7.00^{b}$ & $7.50^{\mathrm{ab}}$ & $7.25^{b}$ & $8.00^{\mathrm{a}}$ \\
\hline & Three & $6.57^{b}$ & $7.25^{\mathrm{ab}}$ & $7.00^{\mathrm{ab}}$ & $7.50^{\mathrm{a}}$ \\
\hline & Six & $6.25^{b}$ & $7.00^{\mathrm{a}}$ & $6.25^{b}$ & $6.75^{\mathrm{ab}}$ \\
\hline & Nine & $6.00^{c}$ & $6.50^{c}$ & $7.25^{b}$ & $8.00^{\mathrm{a}}$ \\
\hline & Twelve & $6.00^{\mathrm{a}}$ & $6.25^{\mathrm{a}}$ & $6.00^{\mathrm{a}}$ & $6.50^{\mathrm{a}}$ \\
\hline \multirow{5}{*}{$\begin{array}{l}\text { General } \\
\text { appearance }\end{array}$} & Zero & $8.50^{\mathrm{ab}}$ & $8.00^{b}$ & $8.00^{b}$ & $9.00^{\mathrm{a}}$ \\
\hline & Three & $8.25^{\mathrm{ab}}$ & $8.00^{b}$ & $7.75^{b}$ & $8.75^{\mathrm{a}}$ \\
\hline & Six & $8.00^{\mathrm{ab}}$ & $7.75^{b}$ & $7.50^{b}$ & $8.50^{\mathrm{a}}$ \\
\hline & Nine & $7.50^{\mathrm{ab}}$ & $7.50^{\mathrm{ab}}$ & $7.25^{b}$ & $8.00^{\mathrm{a}}$ \\
\hline & Twelve & $7.25^{\mathrm{a}}$ & $7.25^{\mathrm{a}}$ & $7.00^{\mathrm{a}}$ & $7.50^{\mathrm{a}}$ \\
\hline
\end{tabular}

*Mean within each row with different letters are significantly different $(p<0.01)$.

**BF: Barley, GG: Guar Gum and XG: Xanthan Gum. 
Assessment of physical properties and sensory attributes of extruded corn snacks mixed with barley and supplemented with (guar and xanthan) gums.

F.A. Ismail, N.H. El-Gazar and D.M. Ali

Fig.(5) Relationship between panelists color score and instrumental b-values of corn snacks.

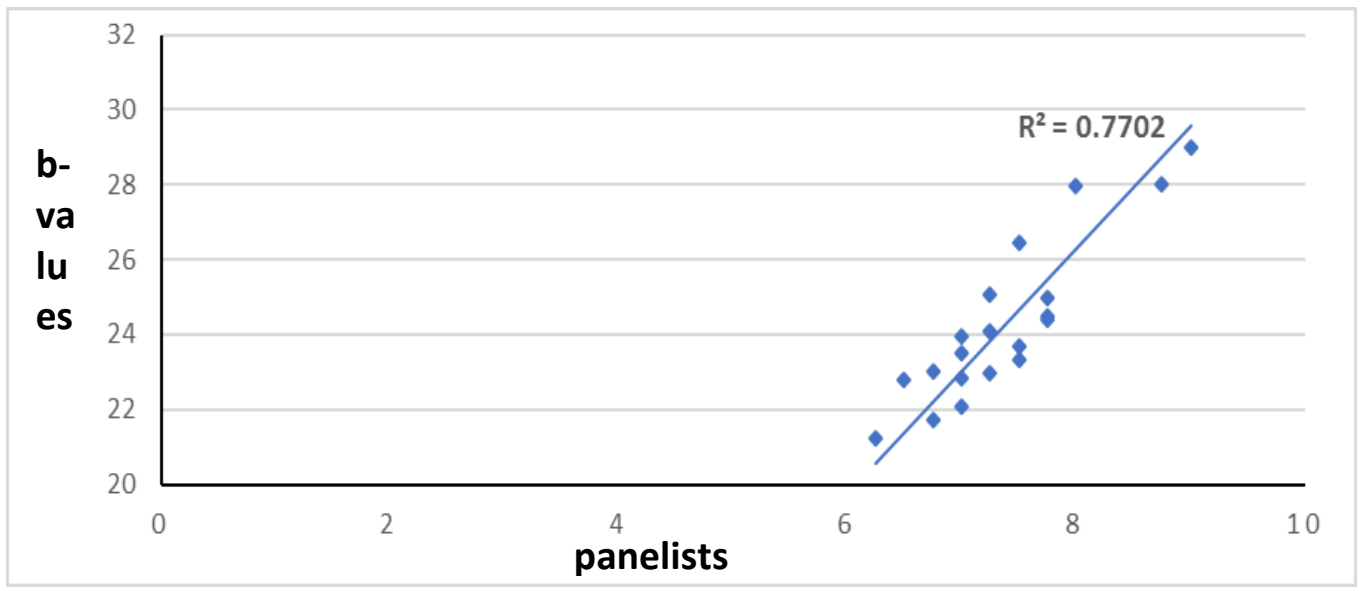

Fig.(6). Relationship between panelists chewiness scores and instrumentals hear force of corn snacks.

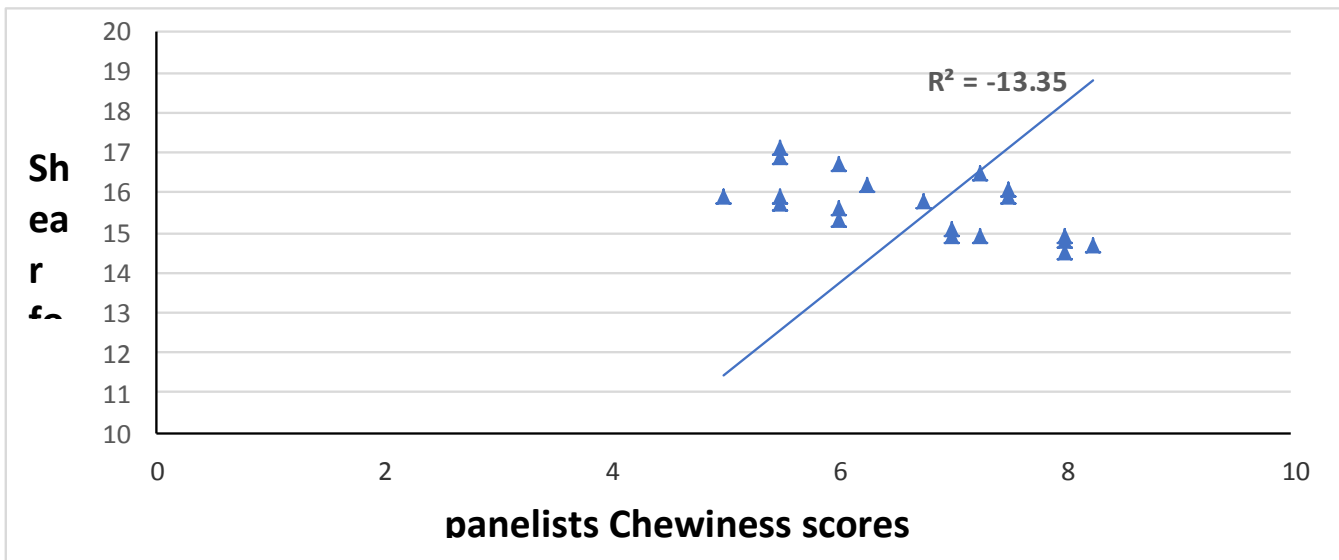

Bulletin of the National Nutrition Institute of the Arab Republic of Egypt. December 2017(50) 23 
Assessment of physical properties and sensory attributes of extruded corn snacks mixed with barley and supplemented with (guar and xanthan) gums.

Fig.(7). Relationship between panelists appearances cores and instrumental expansion ratio of corn snacks.

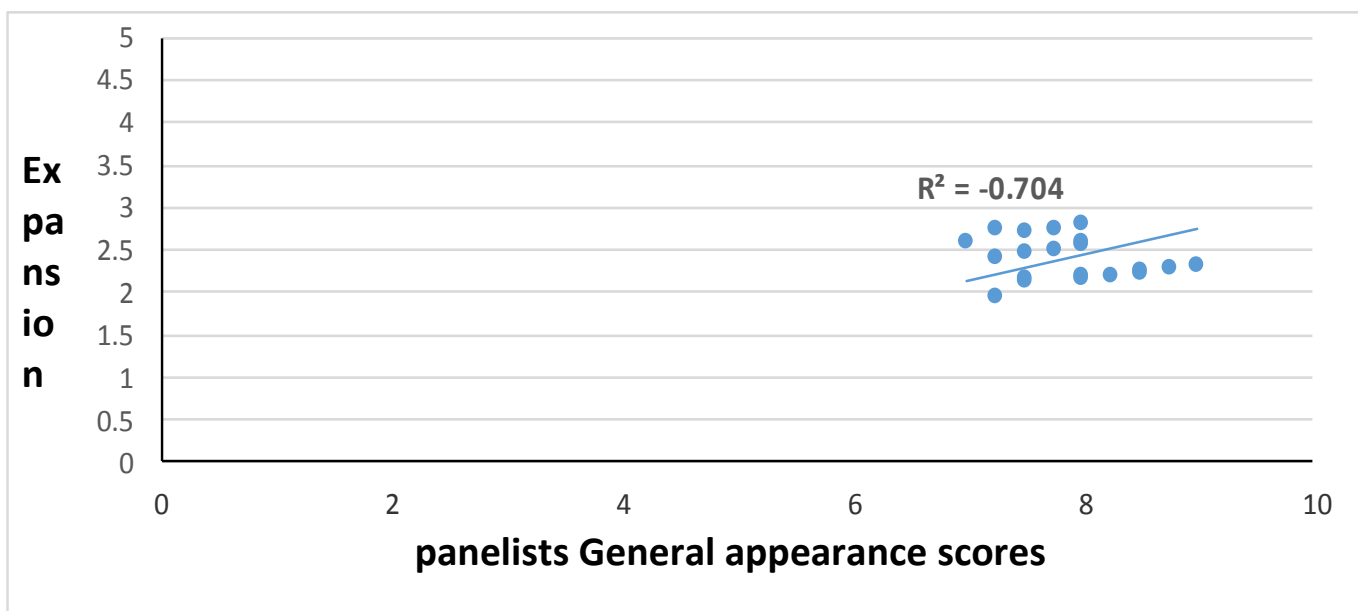




\title{
تقييم الخواص الطبيعية والحسية لوجبات الذرة الخفيفة

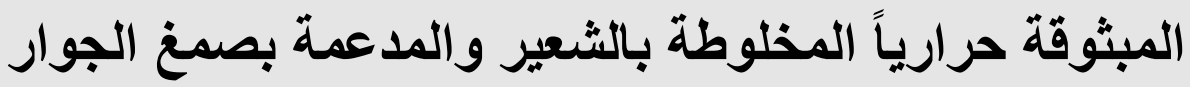 وصمغ الزانثان
}

\author{
فربال عبد العزيز اسماعيل، نجلاء حسن الجزار، دينا محمد على \\ (قسم الصناعات الغذائية، كلية الزر اعة، جامعة القاهرة)

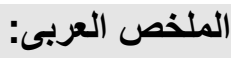

وجبات الذرة الخفيفة التى تم خلطها بلقيق الثعبير بالإضافة إلى صدغ الجوار وصدغ الزانثانتم

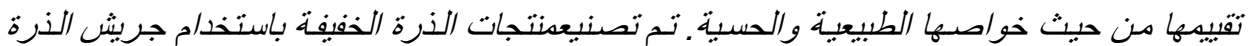

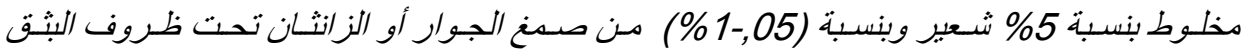

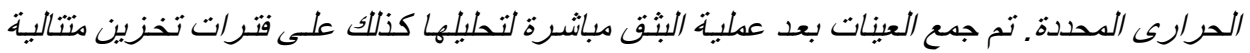

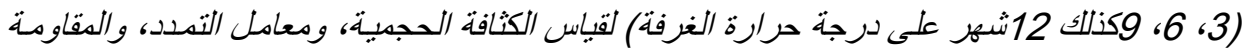

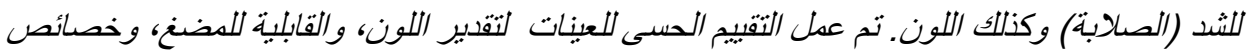

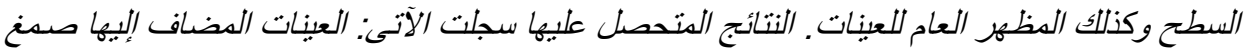

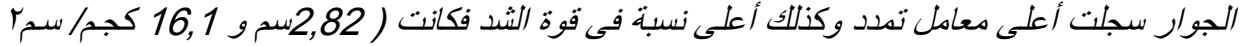

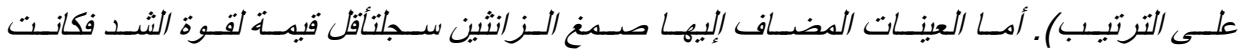

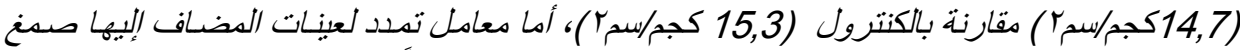

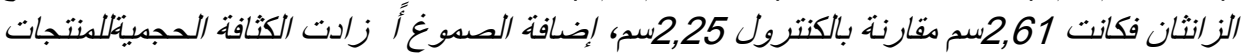

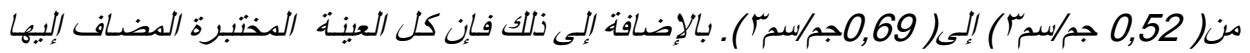

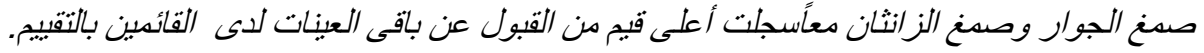
الكلمات المفتاحية: الذرة - الشعبر - صدغ الجوار - صدغ الزانثان 